Hydrol. Earth Syst. Sci., 18, 1105-1118, 2014

www.hydrol-earth-syst-sci.net/18/1105/2014/

doi:10.5194/hess-18-1105-2014

(c) Author(s) 2014. CC Attribution 3.0 License.

\title{
Measuring and modeling water-related soil-vegetation feedbacks in a fallow plot
}

\author{
N. Ursino ${ }^{1}$, G. Cassiani ${ }^{2}$, R. Deiana ${ }^{3}$, G. Vignoli ${ }^{4}$, and J. Boaga ${ }^{2}$ \\ ${ }^{1}$ Department ICEA, University of Padova, Padova, Italy \\ ${ }^{2}$ Department of Geosciences, University of Padova, Padova, Italy \\ ${ }^{3}$ Department dBC, University of Padova, Padova, Italy \\ ${ }^{4}$ Geological Survey of Denmark and Greenland, Groundwater and Quaternary Geology Mapping Department, Lyseng Alle 1, \\ 8270 Hojbjerg, Denmark
}

Correspondence to: N. Ursino (nadia.ursino@unipd.it)

Received: 19 July 2013 - Published in Hydrol. Earth Syst. Sci. Discuss.: 27 August 2013

Revised: 5 February 2014 - Accepted: 7 February 2014 - Published: 21 March 2014

\begin{abstract}
Land fallowing is one possible response to shortage of water for irrigation. Leaving the soil unseeded implies a change of the soil functioning that has an impact on the water cycle. The development of a soil crust in the open spaces between the patterns of grass weed affects the soil properties and the field-scale water balance. The objectives of this study are to test the potential of integrated non-invasive geophysical methods and ground-image analysis and to quantify the effect of the soil-vegetation interaction on the water balance of fallow land at the local- and plot scale.

We measured repeatedly in space and time local soil saturation and vegetation cover over two small plots located in southern Sardinia, Italy, during a controlled irrigation experiment. One plot was left unseeded and the other was cultivated. The comparative analysis of ERT maps of soil moisture evidenced a considerably different hydrologic response to irrigation of the two plots. Local measurements of soil saturation and vegetation cover were repeated in space to evidence a positive feedback between weed growth and infiltration at the fallow plot. A simple bucket model captured the different soil moisture dynamics at the two plots during the infiltration experiment and was used to estimate the impact of the soil vegetation feedback on the yearly water balance at the fallow site.
\end{abstract}

\section{Introduction}

The interaction between soil, water and vegetation begins belowground where the roots grow if enough soil moisture and nutrients are available, creating preferential infiltration flow paths and providing access to water and nutrients to the plant that will grow aboveground. Vegetation type diversity, especially in arid zones, may be ascribed to differences in the way of exploiting subterranean resources and differences in root system morphology (Cody, 1986; Casper and Jackson, 1997; Schenk and Jackson, 2002). Then the interaction continues above the soil surface where the shoots and the leaves shadow the soil and limit the evaporation while transpiration begins. Vegetation reduces the soil moisture content, particularly in the hot season, but it also enhances the soil hydraulic conductivity with its root apparatus (Gish and Jury, 2004; Zimmermann et al., 2006), thus helping to replenish the subsoil water storage and creating a positive feedback system (Franz et al., 2011). When a spontaneously growing species establishes itself on bare land, water-related soil-vegetation feedbacks are often invoked to motivate field-scale soil moisture and vegetation patterns, describe patterns related to eco-hydrological processes and evaluate the associated water budget. Waterrelated feedbacks between the vegetation growth and the water fluxes may have a major impact on the soil moisture balance (Kefi et al., 2007), depending on climate (Baudena et al., 2009; Rietkerk et al., 2011), plant physiology and their survival strategy under water stress (Kurc and Small, 2004, 2007; Ursino, 2007, 2009). 
Agricultural systems provide an opportunity to study the relevant plant-water relations and soil-vegetation feedbacks in a more controlled environment than other natural systems (Jackson et al., 2009). The interplay between soil and vegetation locally alters the hydrologic cycle, and this is a main concern in areas where the water scarcity may become a limiting factor to agricultural production. In those countries where water is scarce, increasing root depth and local infiltration, and reducing evaporation of water from soil are key tasks (Marris, 2008). The interaction between soil and vegetation in rainfed agriculture is crucial to determining the partitioning of rainfall into runoff and infiltration, the connectivity of soil moisture patterns, the recharge of water bodies and ultimately solute transport that are hot topics in understanding the ecohydrological effects of human actions on landscape (Jackson et al., 2009). Repeated measurements of local soil moisture content in space and time can illuminate soil moisture paths, and clarify the nature of relevant spatial processes in catchment hydrology (Grayson and Bloecshl, 2000).

Image analysis is a superior choice for detecting relative change of ground cover, since it facilitates extensive data collection, and reduces human bias by limiting human judgments (Sadler et al., 2010). Image analysis has been successfully applied to ground images, with substantially different objectives, including the classification of soil structures (Gimmi and Ursino, 2004), soil texture (Graham et al., 2005, 2010) and soil cover (Laliberte et al., 2007). The whole spectrum of light may be used to analyze the vegetation responses to external stimuli (Chaerle and Van Der Straeten, 2001). Visualization techniques to monitor plant health include fluorescence (Bushman and Lichtenthaler, 1998; Oxborough, 2004), thermal (Alchanatis et al., 2010; Meron et al., 2010), magnetic resonance and reflectance (Penuelas and Filella, 1998), but among all these techniques, reflectance imaging is the most easily and cost-effectively achievable one, and a customer grade color digital camera offers a low-cost alternative to spectroscopy.

Non-invasive techniques, and particularly groundpenetrating radar (GPR) and electrical resistivity tomography (ERT) provide data at the scale and resolution necessary to understand the hydrological processes of the topsoil. The use of these techniques has been increasingly focused on their ability to measure, albeit indirectly, changes in moisture content (e.g., Binley et al., 2002; Strobbia and Cassiani, 2007; Deiana et al., 2008; Vanderborght et al., 2013 - for reviews see Huisman et al., 2003; Cassiani et al., 2006b) and solute concentration (e.g., Binley et al., 1996; Kemna et al., 2002; Cassiani et al., 2006a; Perri et al., 2012 - for a review see Kemna et al., 2006). Geophysical inspection was coupled here to local measurements of soil saturation to be obtained by Time Domain Reflectometry (TDR) (Topp et al., 1980; Roth et al., 1990), in order to quantify relevant hydrological processes related to vegetation patterns.
In our study, the response of the soil-vegetation system during an irrigation experiment was captured by plot scale maps of the soil moisture variability obtained by ERT. The interest regarding the transient behavior of the flow field following irrigation derives from the comparison of the hydrological response to irrigation of two adjacent plots of an agricultural site located in southern Sardinia, where infiltration, runoff and water storage appeared significantly different. Sardinia has a climate characterized by water deficit at most altitudes during summertime (ARPAS, 2011, 2012). One of the experimental plots was left unseeded for a year and was found barely covered by grass weed at the time of the experiment. The other one was cultivated.

Cassiani et al. (2012) ascribed the different behavior of the two plots to the different interaction between soil and vegetation, envisioning the possibility that feedbacks between water flow and vegetation growth could come into play. The fallow plot had a crusty appearance, and was dry at the surface, evidently as the result of evaporation from the top layer. The soil in the vegetated plot appeared much wetter at the surface, likely due to the shade provided by the vegetation against direct sunlight. Unlike those of the cultivated plot, the deeper soil layers of the bare plot seemed to be wet before irrigation. New experimental data and a reinterpretation of previously published data are presented here. The data presented in the following sections have been partly presented in Cassiani et al. (2012). However the analysis of these data is conducted with different methods (e.g., using time-lapse inversion of ERT data) and it is focused primarily on the behavior of the fallow plot. The re-analysis of ERT data, using ratio inversion, highlights the problem in a manner not previously appreciated using standard ERT inversion and suggests that runoff was overestimated by Cassiani et al. (2012) since, by neglecting water salinity and temperature, the soil saturation was underestimated by the ERT measurement in the fallow plot. In the following sections, we try to use for the first time a combination of VIA (Visual Image Analysis) and local TDR measurements to highlight the local infiltration to be attributed to a soil vegetation feedback and to evaluate the impact of this feedback on the yearly water balance. Crucial water-related soil-vegetation feedbacks are often conjectured and rarely quantified by dedicated experiments. The hydrological response of the fallow plot is discussed with major focus on the soil vegetation interaction and the water budget. Coupling hydrological and biological databases is a promising way to test ecohydrological modeling concepts (Garre et al., 2012). Thus, first we model the infiltration experiment and compare the model outcome with the TDR measurements, and then we extend the simulation time in order to infer the impact of the positive feedback on the annual water balance. The new bucket model presented here differs substantially from the one described by Cassiani et al. (2012), with respect to the characteristic timescale. Cassiani et al. (2012) analyzed the impact of a positive feedback between vegetation growth and infiltration 
on a timescale of several decades. Thus the biomass balance came into play and the authors demonstrated that if the feedback exists, there may be a characteristic root length that maximizes the biomass production in a water scarcity scenario, and the estimated optimum root length was approximatively equal to the observed one.

By simulating the yearly water balance, we suggest that the patchy vegetation that grows on the bare soil may rely on the water stored before the growing season, thanks to the preferential infiltration that occurs where the vegetation grew before, creating a discontinuity in the upper crusty soil layer. This old water, together with the new one infiltrating during the growing season when it rains, may correspond to the effective evapo-transpiration volume, provided that transpiration is restricted to the deeper soil layers below the crusty one due to typical weed root distribution (Cassiani et al., 2012). The fact that water is stored in the soil for months could support and validate our intuition of the relevant impact of salinity on the ERT measurements and advance our comprehension of the functioning and maintenance of the ecosystem under study.

\section{Methods}

\subsection{Experimental setup}

A 4-day monitoring following an irrigation test was performed at an agricultural experimental farm located in Sardinia, Italy, as part of the EU-FP7 CLIMB project (Ludwig et al., 2010), focused on the analysis of climate change impact on the hydrology of Mediterranean basins. The irrigation lasted for 1 night (approximately $8 \mathrm{~h}$ ), with a total of $42 \mathrm{~mm}$ of applied artificial rainfall on both plots.

The experiment took place at the San Michele farm near Ussana, in the Rio Mannu Catchment (southern Sardinia). The basin ranges in elevation from 62 to $842 \mathrm{~m}$ a.s.l. (meters above the sea level) with an average of $295.5 \mathrm{~m}$ a.s.l. The basin is mainly covered by crop fields and grassland, while only a small percentage of its area is occupied by forests in the southeastern part of the basin. The farm area has a gentle topography and is part of the Campidano Plain. According to the World Reference Base for Soil Resources (WRB), the relevant soils present at this site are (Brown soils) Cambisols (CM), Regosols (RG) and Vertisols (VR).

The island of Sardinia has a climate characterized by a water deficit at most altitudes. In the southeastern part of Sardinia where Ussana is located, the water deficit is maximum in summer, while the soil moisture availability is at its maximum in wintertime. The hydrological regime is characterized by wet periods from October to April, where more than $90 \%$ of the rainfall is accumulated, and very dry summers (MaySeptember). The yearly average temperature is $16^{\circ} \mathrm{C}$. And the effective soil moisture availability ranges from $100 \%$ of the field capacity during winter to $0-10 \%$ in summertime (ARPAS, 2011, 2012).

The controlled irrigation experiment was undertaken in May 2010. During the period October 2009September 2010, the cumulate rainfall at the site was $300 \mathrm{~mm}$, and the temperature ranged from 10 to $30^{\circ} \mathrm{C}$.

\subsection{Plot-scale soil moisture measurements}

Using three ERT lines, the detailed soil moisture response of the system from the controlled irrigation was captured. Both bare and cultivated plots were irrigated with the same amount of water. Each ERT line is composed of 24 electrodes spaced $20 \mathrm{~cm}$ apart, for a total length of $4.6 \mathrm{~m}$ each, and an expected depth of investigation not exceeding $1 \mathrm{~m}$. Two lines were left in place throughout the experiment until 4 days after irrigation ended in the bare plot; one was left in place in the cultivated plot. Time-lapse measurements were taken periodically, using a dipole-dipole skip 0 scheme and full acquisition of reciprocals to estimate the data error level (see e.g., Binley et al., 1995; Cassiani et al., 2006a; Monego et al., 2010). Consistently, the data inversion used an Occam inversion approach as implemented in the ProfileR/R2/R3 software package (Binley, 2011) accounting for the error level estimated from the data themselves. At each time step, between 90 and $95 \%$ of the dipoles survived the 5\% reciprocal error threshold. In order to build a a time-consistent data set, only the dipoles surviving this error analysis for all time steps were subsequently used, reducing the number to slightly over 200 dipoles (i.e., between 80 and $90 \%$ of the total) at all three ERT lines. The absolute inversions were run using the same $5 \%$ error level. Time-lapse inversions were run at a lower error level equal to $2 \%$ (consistently with the literature - e.g., Cassiani et al., 2006a).

\subsection{Local soil moisture measurements}

Short time monitoring of soil moisture was aimed at finding the interrelations between vegetation density, soil structure and water flow at the local scale. The local soil saturation monitoring was acquired by permanently vertically installed TDR probes (probe lengths of 32 and $50 \mathrm{~cm}$ ) monitored with a Tektronix 1502 instrument in the two plots (Fig. 1), and by a portable TDR (Trase) Soil Moisture Measurement System (Campbell Scientific) equipped with $21 \mathrm{~cm}$ rod length at 15 points distributed over the bare plot that was $5 \mathrm{~m}$ long and $3 \mathrm{~m}$ wide (Fig. 2).

Repeated measurements at the 15 reference locations in the fallow plot were taken only once before irrigation (after a small rain event of about $13 \mathrm{~mm}$ occurred the night preceding the irrigation experiment) with a portable Trase (21 cm rod length). Unfortunately, the Trase failed after the first background measurement. During the 3-day period of time following irrigation, additional repeated measurements were acquired at the 15 reference locations of the plot over 

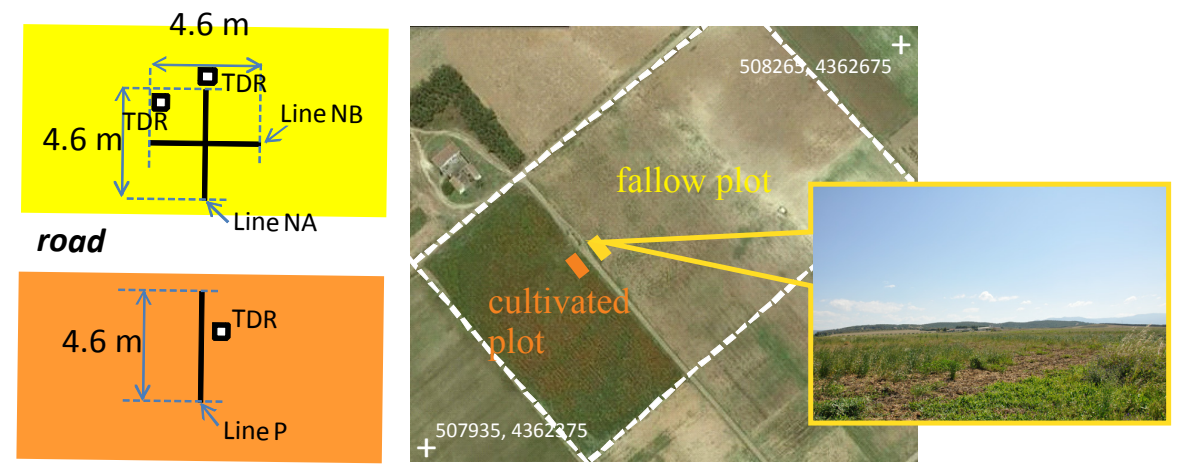

Fig. 1. The experimental site.

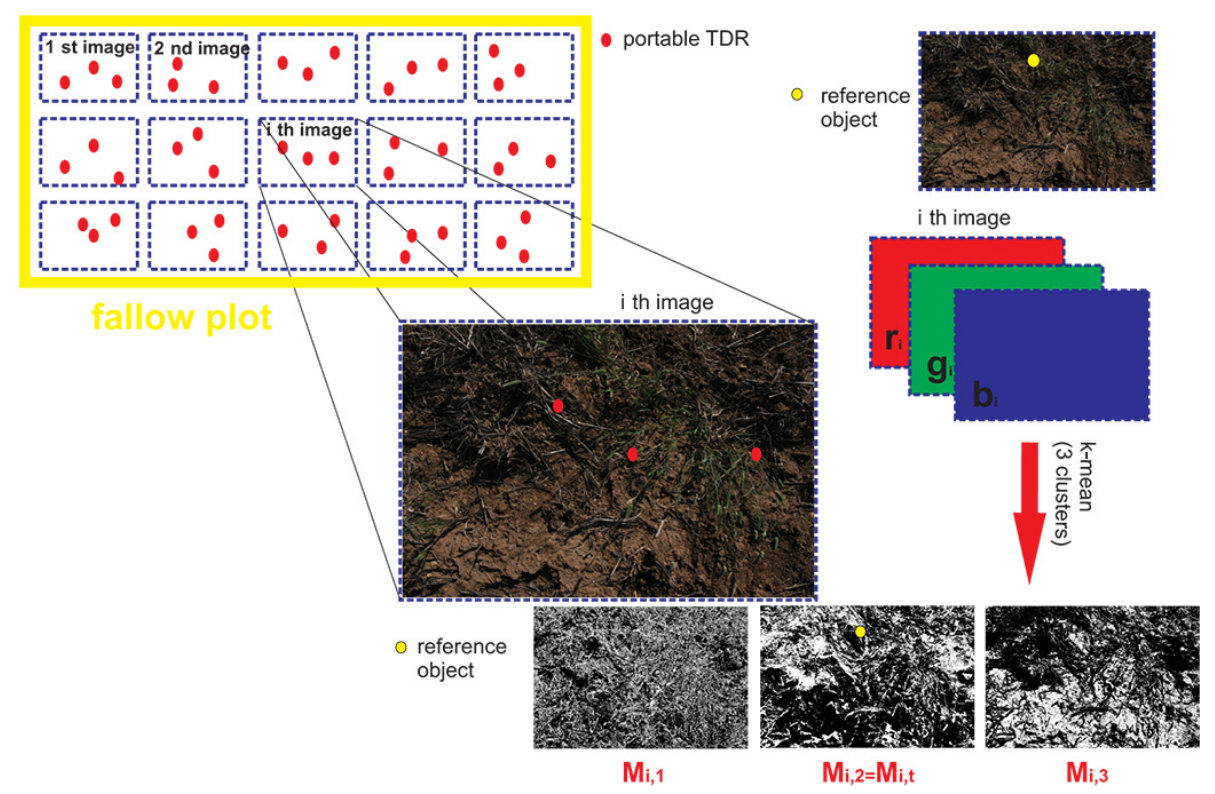

Fig. 2. Local measurements of vegetation density and soil moisture by combined VIA and repeated TDR measurements.

a different control depth (32 cm probes), always near solar noon.

\subsection{Local measurements of vegetation density}

The day before irrigation, a set of 15 vertical ground photographic images of a $0.9 \times 0.6 \mathrm{~m}^{2}$ surface of soil were collected near solar noon in cloud-free conditions, each centered at the 15 TDR acquisition locations of the fallow plot using a Nikon D90 camera (Fig. 2). Vegetation cover was estimated by VIA and associated with the corresponding local TDR measurement of soil moisture. Note however that "there is no universal theory on color image segmentation yet", and "all of the existing color image segmentation approaches are, by nature, ad hoc." (Cheng et al., 2001)

We used the IDL7.1, a programming language developed by ITT (2009) for making automated cover detection by $k$ means (MacQueen, 1967), and secondly to estimate the vegetation greenness on rangeland (that we use here to evaluate the goodness of the estimate of local vegetation density). 
Each $i$ th image was processed in order to obtain NC complementary binary images $\left(M_{i, j}\right)$ that are referred to as masks, with $j$ ranging from 1 to the number of clusters NC that was used to parameterize the $k$ means algorithm. The optimum number of cluster (NC) is site specific. A reference object of interest (e.g., a leaf) is chosen in each picture. The targeted mask $\left(M_{i, t}\right)$ that contains the reference object is used to evaluate the vegetation cover $\mathrm{CC}=\left\langle M_{i, t}>\right.$ as the average $(<>)$ of the mask's pixel values (Fig. 2). Furthermore, the vegetation greenness is evaluated as a function of the average normalized red $\left(r_{i}\right)$, green $\left(g_{i}\right)$ and blue $\left(b_{i}\right)$.

Borzuchowski and Schulz (2010) revise a list of vegetation spectral indices to describe plant eco-physiological parameters. None of them can be estimated in the visible spectrum, due to its restricted range of reflectance. However, we adapted the vegetation spectral index concept to the VIA data and defined the following greenness index:

$F=\frac{<r_{i} \cdot M_{i, t}>-<g_{i} \cdot M_{i, t}>}{<r_{i} \cdot M_{i, t}>+<g_{i} \cdot M_{i, t}>}$,

where $<r_{i} \cdot M_{i, t}>$ and $<g_{i} \cdot M_{i, t}>$ are the average value of the normalized red and green of the non-zero pixels in the targeted mask $M_{i, t}$ (the one that contains the reference object and is used to estimate the vegetation cover). Since the vegetation cover is discontinuous but homogeneously green at the plot scale and at the time of the experiment, we expect $F$ to be quite homogeneous, unless the targeted mask contains intermixed soil and vegetation objects and in this sense, we used $F$ to estimate the reliability of the segmentation procedure. Visual Image Analysis (VIA) was used here to repeatedly detect ground cover and to relate local biomass density to soil moisture dynamics in a fallow plot sparsely covered by grass weed. Repeated measurements of soil moisture and biomass density during an irrigation experiment allowed us to detect substantially different soil moisture and vegetation paths in fallow and cultivated plots.

\subsection{Water balance model}

We set up a simple bucket model to address the two-way interaction between plants and soil in water-controlled ecosystems according to the experimental evidence provided by ERT, TDR and VIA. Even though the focus was on the fallow plot, we used the model to also reproduce the soil moisture dynamics of the adjacent cultivated plot during the irrigation experiment for comparison.

Kurc and Small $(2004,2007)$, found that evapotranspiration is largely correlated with surface soil moisture, not to root zone soil moisture, and suggested that evaporation is dominant over transpiration within the top $15 \mathrm{~cm}$ of soil, whereas evaporation has a minor influence on soil moisture below about $15-20 \mathrm{~cm}$.

We assume that after small rain events, a shallow upper soil layer (USL) acts as a temporary storage for water that is entirely returned to the atmosphere through soil evaporation.

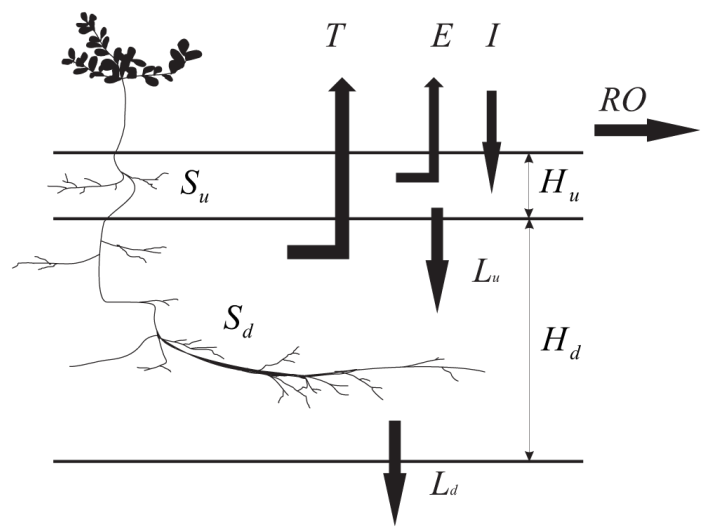

Fig. 3. Scheme of the conceptual model.

Furthermore, we assume that excess rainfall leaching from the USL supplies a deeper reservoir that we refer to as the deep soil layer (DSL) where roots have exclusive access to soil moisture leading to transpiration, even when the upper soil layer is empty. The root architecture determines which soil layer contributes more to transpiration, the choice that we made was motivated by the observation that weed roots appeared mostly concentrated in the DSL (Cassiani et al., 2012).

The growth of the vegetation is associated to the formation of macroporosity in the USL, leading to a local increase of hydraulic conductivity (soil-vegetation feedback) and leakage of excess water into the DSL, even if the USL is poorly conductive (crusty). In the absence of vegetation we do not expect any water flux to take place at the interface between the two layers due to the presence of the sealing crust. Even though cracks may develop in completely bare soils, we neglect here this possibility and compare the eco-hydrological behavior of the fallow plot with a hypothetical worse case scenario (bare soil) occurring when the DSL is disconnected from the atmosphere, in order to evaluate the impact of the soil-vegetation feedback on the annual water balance. We identify the USL's depth with $H_{\mathrm{u}}=100 \mathrm{~mm}$ and the DSL's depth with $H_{\mathrm{d}}=500 \mathrm{~mm}$, according to the root depth estimated by Cassiani et al. (2012), and the effective saturation of the two layers with $S_{\mathrm{u}}$ and $S_{\mathrm{d}}$, respectively (Fig. 3).

The daily water balance within the USL is expressed by the following differential equation:

$\frac{\partial \theta}{\partial t}=n \cdot \frac{\partial S_{\mathrm{u}}}{\partial t}=\frac{1}{H_{\mathrm{u}}} \cdot\left(P+I-\mathrm{RO}-E-L_{\mathrm{u}}\right)$,

where $\theta$ is the soil moisture content, $n=0.4$ is the soil porosity, $P$ is the daily precipitation, $I$ is the irrigation, and RO is surface runoff. The evaporation $E$ was evaluated with a modified dual crop coefficient approach (Allen et al., 1998),

$E=\mathrm{ET}_{0} \cdot\left[K_{\mathrm{r}} \cdot\left(1-K_{\mathrm{b}} \cdot \mathrm{CC}\right)\right]$,

where $\mathrm{ET}_{0}$ is the reference evapotranspiration evaluated using the Penman-Monteith equation, $K_{\mathrm{b}}$ is the basal crop 


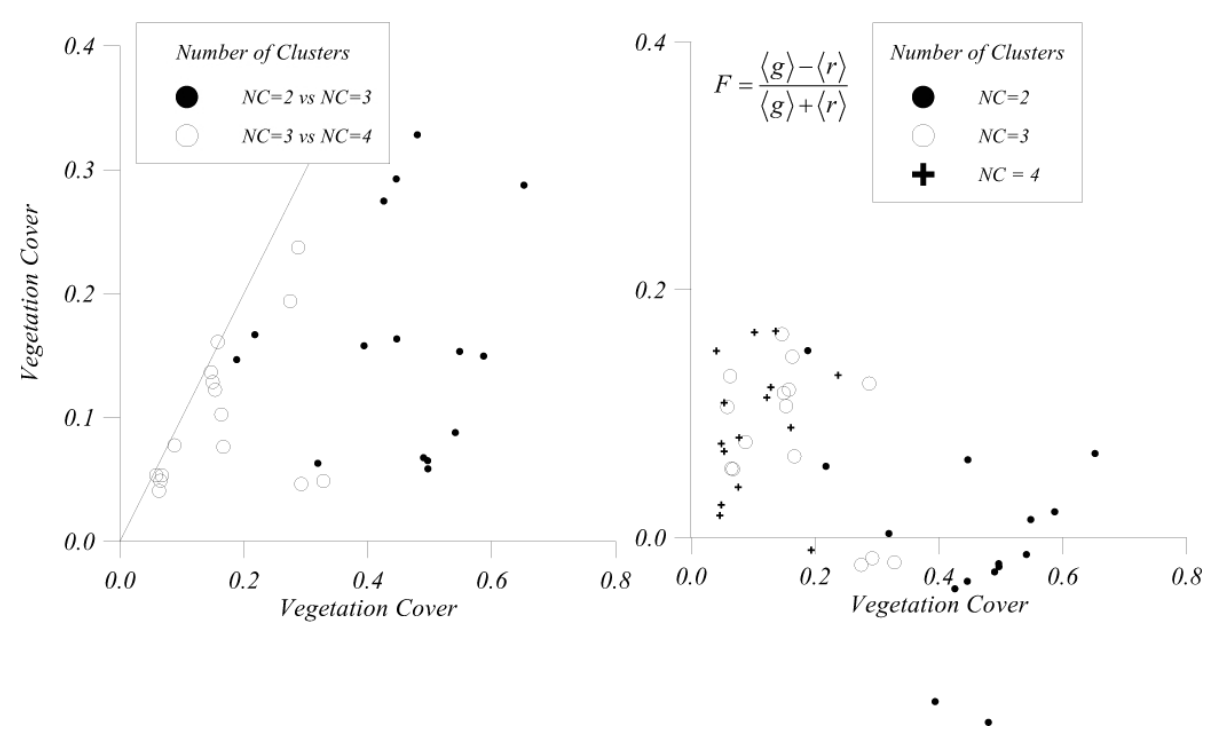

Fig. 4. Vegetation cover evaluated by image analysis with different number of clusters NC (see legend) and vegetation greenness $F$.

coefficient, $K_{\mathrm{r}}$ is the evaporation reduction coefficient linearly decreasing from 1 to 0 with the USL's saturation when the soil water content is $\theta_{\mathrm{WP}}<\theta<0.5 \cdot \theta_{\mathrm{FC}}$; where $\theta_{\mathrm{FC}}=0.28$ is the soil moisture content at field capacity and $\theta_{\mathrm{WP}}=0.1$ is the soil moisture content at wilting point. Excess water percolates into the deeper soil layer, leading to the leakage $\left(L_{\mathrm{u}}\right)$ unless the soil is completely bare. In Eq. (3) CC is the vegetation cover that we estimated by VIA.

The daily soil moisture balance within the DSL is expressed by the following differential equation:

$\frac{\partial \theta}{\partial t}=n \frac{\partial S_{\mathrm{d}}}{\partial t}=\frac{1}{H_{\mathrm{d}}} \cdot\left(L_{\mathrm{u}}-T-L_{\mathrm{d}}\right)$,

where the transpiration $(T)$ evaluated according to the dual crop coefficient approach (Allen et al., 1998) as

$T=\mathrm{ET}_{0} \cdot\left[K_{\mathrm{b}} \cdot K_{\mathrm{S}} \cdot \mathrm{CC}\right]$.

The stress coefficient $K_{\mathrm{S}}$ is a linear function of the DSL's saturation between the readily available soil water in the root zone RAW and the total available soil water in the root zone TAW. According to Allen et al. (1998) we set

$\mathrm{TAW}=\left(\theta_{\mathrm{FC}}-\theta_{\mathrm{WP}}\right) \cdot H_{\mathrm{u}}$

and

$\mathrm{RAW}=p \cdot \mathrm{TAW}$

with $p=0.3$ in the cultivated plot, and $p=0.7$ in the fallow plot (partially covered by grass weed) (Allen et al., 1998). Leakage out of the control volume $L_{\mathrm{d}}$ may be reasonably neglected under water scarcity conditions (Keating et al., 2002; Zhang et al., 2001).

\section{Results}

\subsection{Estimate of vegetation cover by VIA}

Repeated measurements in space of the vegetation cover CC were obtained by VIA. The optimum number of cluster NC was chosen in order to achieve positive and homogeneous estimates of the vegetation greenness $F$ (Fig. 4, right panel). We observed that when $\mathrm{NC}=2$ (the objects are vegetation and soil) the vegetation cover may be overestimated with respect to the result obtained with a larger number of clusters (Fig. 4, left panel, bold circles) and if pixels belonging to the soil class are classified as vegetation, $F$ varies significantly, switching from negative to positive values, meaning that the segmentation outcome is unreliable. Further increasing the $\mathrm{NC}$ from 3 to 4 may induce an error in the evaluation of the vegetation cover due to the fact that the pixels belonging to the vegetation class split into subclasses of slightly different color, and this results in an underestimate of the actual vegetation cover in a few cases (Fig. 4, left panel, open circles). Figure 4 (right panel) shows that when $\mathrm{NC}=3$ and $4, F$ varies less, indicating that objects belonging to the targeted mask could be more homogeneous and belong to the "vegetation class" as we would expect. For these reasons we set $\mathrm{NC}=3$ and estimated that the vegetation cover varies from point to point, ranging between 0 and 0.4. The estimate of CC obtained with different color representation (e.g., IHS, not shown here) was consistent with the results presented in this section.

\subsection{Observed soil moisture dynamics at the plot scale}

Two perpendicular ERT lines (NA and NB) were placed in the fallow plot and measurements were taken repeatedly over 

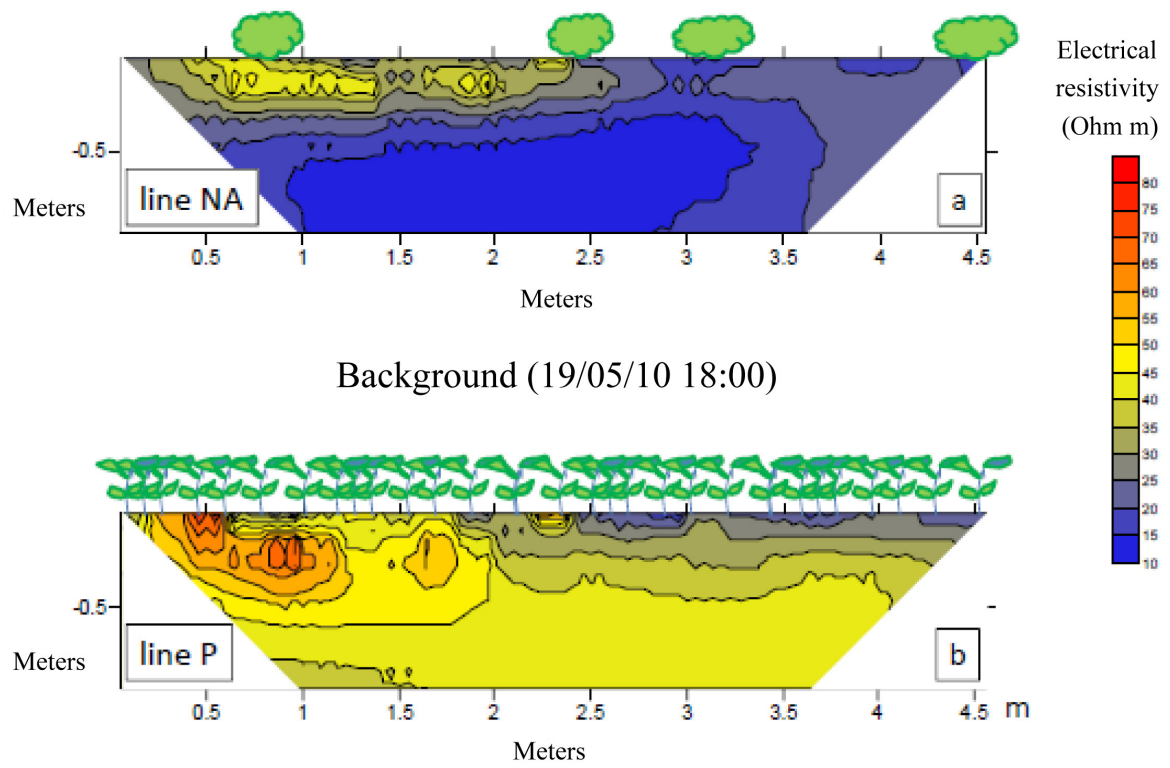

Background (19/05/10 18:00)

esistivity

Ohm $\mathrm{m})$

Fig. 5. Background images of the fallow (a) and of the adjacent cultivated (b).

time before and after the irrigation experiment. The background ERT image (collected on 19 October 2010 - see e.g., line NA in Fig. 5a) shows a profile where a very resistive soil layer, about $20 \mathrm{~cm}$ thick and corresponding to a visually apparent crust of dry material, overlies a much more electrically conductive subsoil. This is in sharp contrast with the ERT profile acquired on the nearby cultivated plot (Fig. 5b) where the presence of vegetation cover maintains a higher moisture content (and electrical conductivity) in the top soil, whereas vegetation depletes the moisture content of the deeper layer where the roots exert their suction. This result indicates that in the fallow plot vegetation shadowing may be neglected, thus the upper soil layers are exposed to significant evaporation. Following a minor rainfall event $(13 \mathrm{~mm})$ the night of 19-20 May 2010 and the irrigation experiment the night of 21-22 May 2010 (42 mm), no major change in electrical resistivity was observed in this fallow plot, as opposed to the dramatic change observed in the nearby vegetated field (see Cassiani et al., 2012 for a thorough discussion). In the present paper, a new, detailed analysis of resistivity changes based on a ratio inversion approach (see e.g., Cassiani et al., 2006a) reveals the details of the subtle changes caused by irrigation to the resistivity patterns of the subsoil in the patchy plot. The results along lines NA and NB, thus coming from totally independent measurements, are consistent with each other and are shown in Fig. 6. From this figure it is apparent that (a) the natural rainfall, consisting of roughly $13 \mathrm{~mm}$ that occurred during the night between 19 and 20 May 2010, causes essentially no changes in the electrical resistivity profiles (see Fig. 6). We can conclude that nearly the entire precipitation must have resulted in surface runoff, with direct evaporation from local ponding in the field and along the dirt road; (b) the irrigation experiment in the night between 21 and 22 May with an amount of $42 \mathrm{~mm}$ of irrigated water, causes two changes in the resistivity profiles in the patchy plot: (i) a resistivity increase is apparent, albeit somehow discontinuous, in the soil layer between 10 and $50 \mathrm{~cm}$ depth. The increase is as high as about $25 \%$ of the original resistivity of the same soil before irrigation; resistivity decrease, also in the $25 \%$ range, is observed below $50 \mathrm{~cm}$ depth. Here too the patterns appear discontinuous. This evidence is, at first, confusing. How can the addition of water increase the resistivity of the layer in the top $10-50 \mathrm{~cm}$, while decreasing at the same time the resistivity below? A first tentative explanation may attribute this result to an artefact caused by the physical size (length) of the electrodes that penetrate the ground for a depth (a few centimeters) that is non-negligible with respect to the electrode separation $(20 \mathrm{~cm})$. The wetting of the soil top layer, and consequently the increase of its electrical conductivity, may act as a shortcut that cannot be fully accounted for by the inversion algorithm, that assumes that the electrodes are point-like. As the current is short-circuited in the top few centimeters, the underlying soil may appear more resistive than it actually is, thus potentially causing the observed resistivity increase of the region below $10 \mathrm{~cm}$. This hypothesis, however, fails to explain why the underlying decrease of resistivity below $50 \mathrm{~cm}$ is still perfectly detectable. Also, the changes in resistivity $( \pm 25 \%)$ are too subtle to be attributed to an artefact caused by short-circuiting. A second, more sound, explanation is to relate these changes in soil electrical resistivity to factors other than moisture content alone. Two other factors, namely pore water salinity and temperature changes, can play a role. In fact, it is not uncommon to 


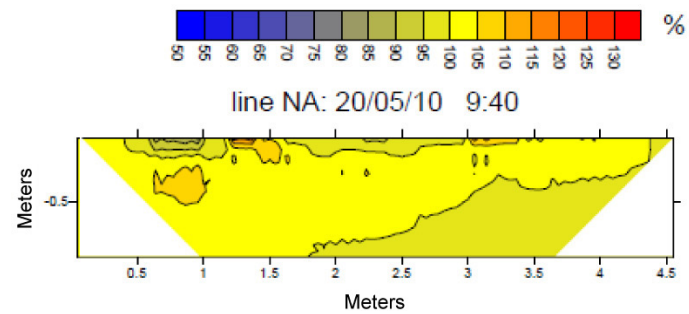

$\%$ resistivity change w.r.t. background $(19 / 05 / 10)$

line NA: 22/05/10 10:30
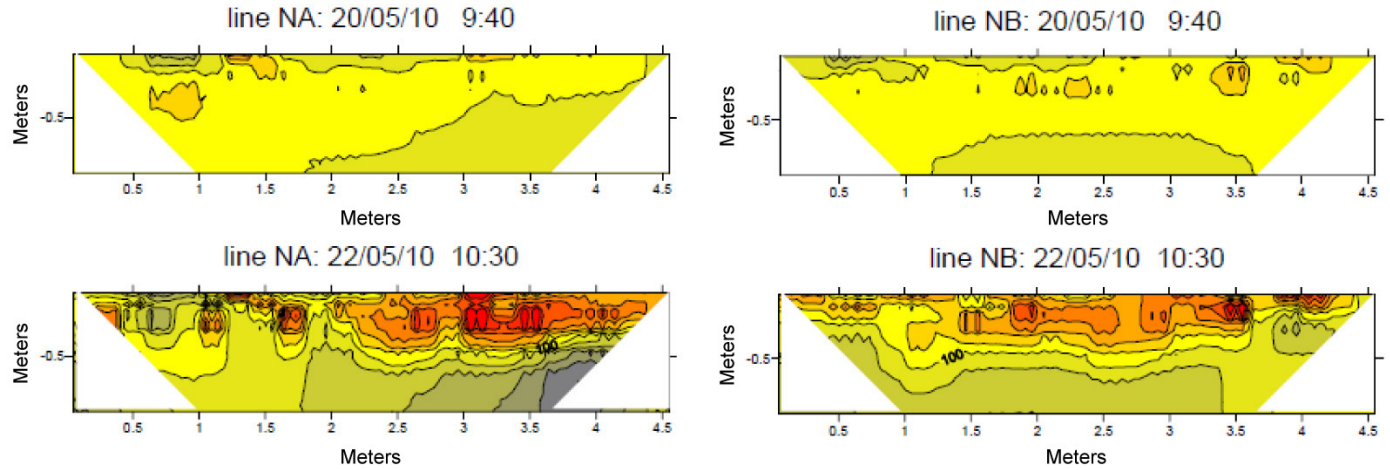

line NB: 22/05/10 10:30

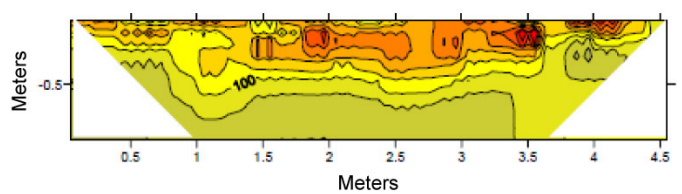

line NA: 23/05/10 9:40
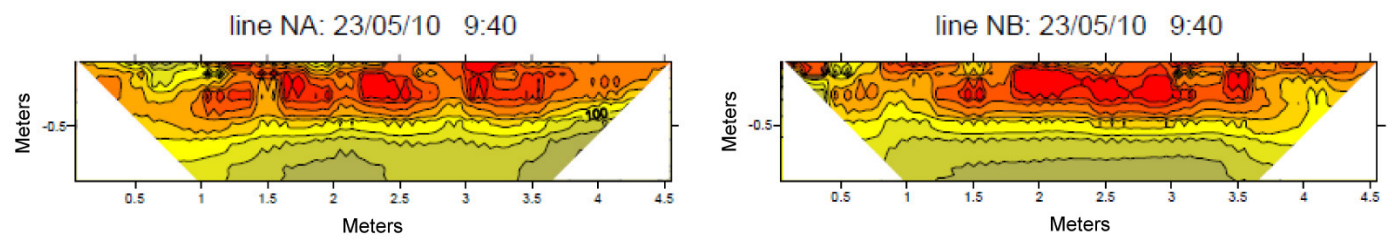

line NA: 24/05/10 15:35
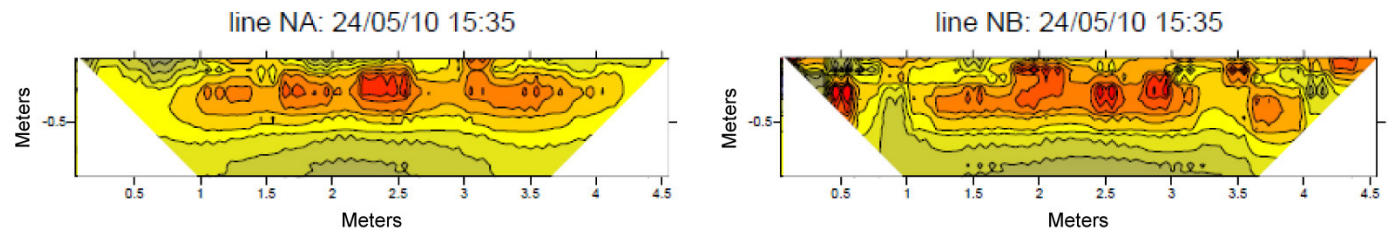

Fig. 6. ERT measurements along lines NA (left panels) and NB (right panels) in the fallow plot at different times. Top to bottom panels: background, after irrigation (22 May 2010, 10:30 LT), 1 day after irrigation (23 May 2010, 09:40 LT), more than 2 days after irrigation (24 May 2010, 15:35 LT).

observe that intense precipitation events have the effect of reducing soil bulk electrical conductivity by displacing the in situ pore water whose solutes have had the time to reach an equilibrium with the soil components, or that had different temperature (see e.g., Cassiani et al., 2006a). The incoming precipitated water pushes down the existing pore water in a sort of piston-like effect (see also Winship et al., 2006), thus causing a decrease in electrical conductivity in the upper part of the profile (Mojid and Cho, 2008) and an increase in the lower part, totally analogous of our observations here. Indeed, this hypothesis is confirmed by the evidence from the TDR probes permanently installed in the fallow plot (Fig. 7): the $50 \mathrm{~cm}$-long sondes, covering the entire thickness where a resistivity increase is observed, show no average change in moisture content after rainfall or irrigation. On the contrary, the shorter sondes $(32 \mathrm{~cm})$ show an increase in moisture content after irrigation.

We observe the apparently paradoxical situation where average moisture content remains largely unchanged in the top $50 \mathrm{~cm}$, while correspondingly the resistivity of the same layer is decreased by about $20 \%$ and the resistivity of the underlying layer is increased also by roughly the same percentage. This phenomenon can find an explanation only if a second cause of resistivity change is called into play, in addition to moisture content change. The influence of this second cause

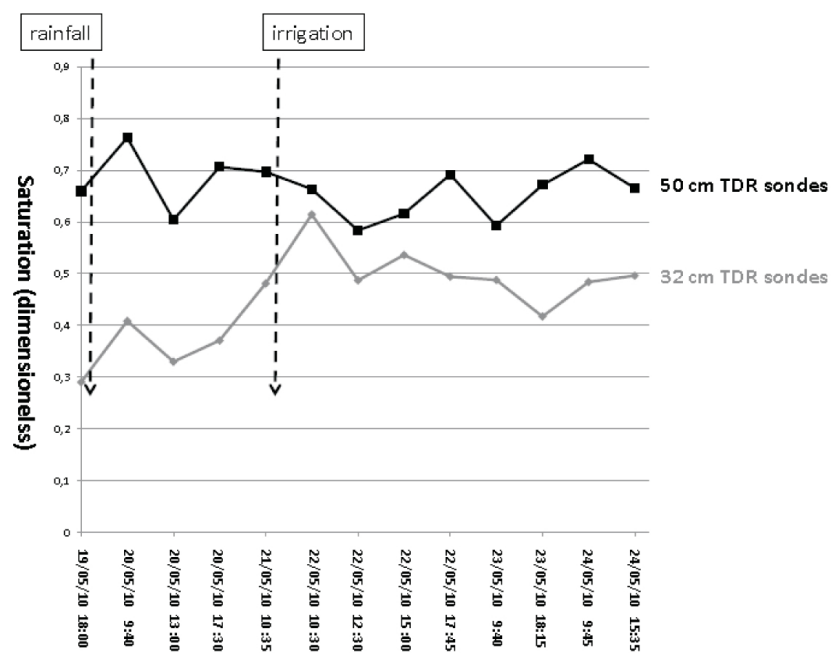

Fig. 7. Fallow plot soil saturation measured by fixed 50 and $32 \mathrm{~cm}-$ deep TDR probes at different times.

is strong enough to overturn the influence of moisture content change itself. The possible causes may be substantially only two: a decrease in pore water salinity, and/or a decrease in soil temperature. We are not in a position to decide which mechanism is prevailing. In both cases, however, salinity or 


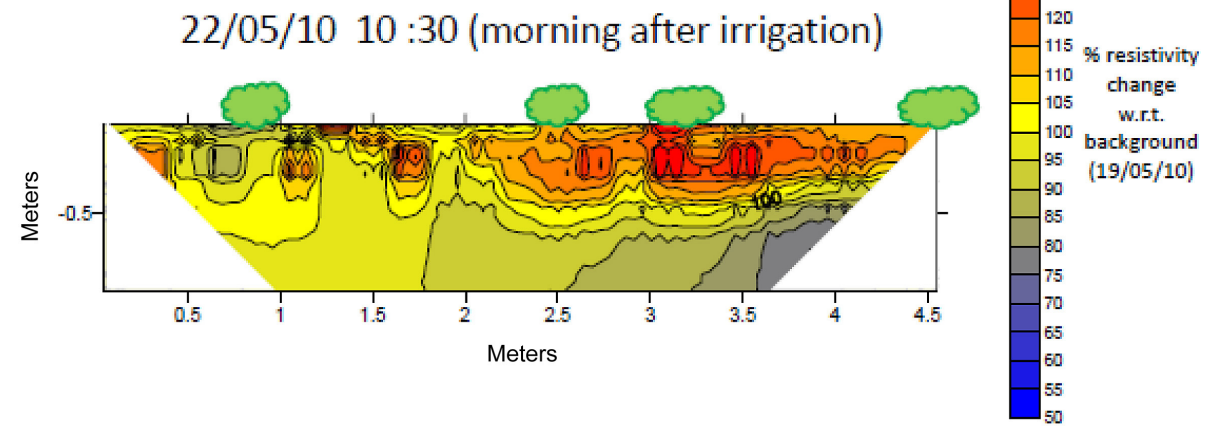

Fig. 8. Plant distribution along ERT line NA (fallow plot).
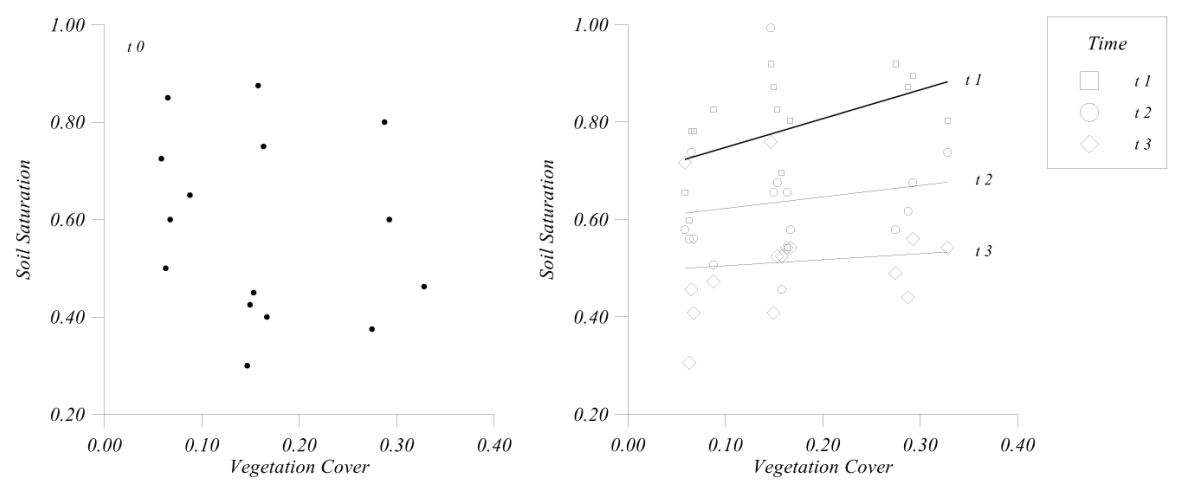

Fig. 9. Left panel: vegetation cover (CC) versus soil saturation after rainfall. Soil saturation is measured by portable TDR (rod length $21 \mathrm{~cm}$ ). $t_{0}$ : 21 May, 10:30 LT - (bold circles). Right panel: vegetation cover versus soil saturation at different times after irrigation. Soil saturation is measured by TDR (rod length $=32 \mathrm{~cm}$ ). $t_{1}: 22$ May, 11:30 LT (squares); $t_{2}: 23$ May, 09:30 LT (open circles); $t_{3}: 24$ May, 10:30 LT (diamonds).

temperature (or both) act as tracers, marking the new water versus the old water already in the system. This "new" water pushes down the existing pore water and a mixture of old and new water reaches deeper zones, as apparent in Fig. 6.

Figure 8 shows a comparison between the location of the individual plants along the profiles and the time-lapse images along the ERT line NA, particularly the one relevant to the morning after the end of irrigation. There is some correlation between the location of major changes (especially on the right-hand side of the profile) and the plant location. Note however that this analysis neglects the 3-D effects that are possibly linked to the location of patchy vegetation off the individual ERT lines.

\subsection{Feedbacks between vegetation growth and soil moisture dynamics}

In order to get more evidence on the key interrelations between the spatially variable soil moisture and vegetation density, in Fig. 9 we compared the repeated measurements of vegetation cover obtained by VIA (with $\mathrm{NC}=3$ ) with the corresponding measurements of the soil saturation obtained by portable TDR. After the small rainfall event, the soil saturation of the upper $20 \mathrm{~cm}$-thick soil layer was measured by Trase. The soil saturation appeared to be not at all correlated with the vegetation cover (Fig. 9, left panel).

In the 3 days following the irrigation, the soil saturation was measured using $32 \mathrm{~cm}$-long probes. Shortly after irrigation the vegetation cover and the soil saturation were positively correlated (Fig. 9, $t=t_{1}$ ), but the correlation was very weak. Already 1 day after irrigation (Fig. 9, $t=t_{2}$ ), the results seem to indicate that redistribution took place because the soil saturation homogenized (the slope of the fit line changes) and evapotranspiration came into play (the fit lines shift downward). This result poorly supports the hypothesis that there is a positive feedback between vegetation growth and preferential infiltration, before redistribution could take place and just suggests that a positive feedback could exist. Only a larger data set could have allowed stronger conclusions on the existence of positive soil-vegetation feedbacks. The soil moisture reduction of about 0.1 in 3 days that was measured by TDR almost approaches the potential evapotranspiration that was $4.5 \mathrm{~mm} \mathrm{~d}^{-1}$ at the time of the experiment (the estimated evaporation and transpiration were 2 and 

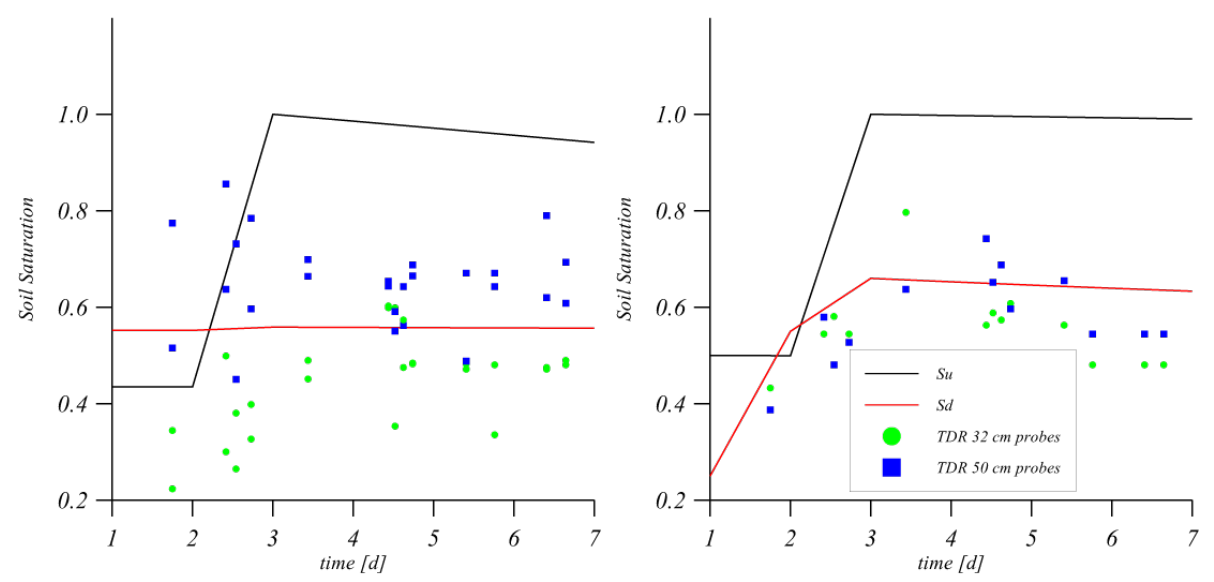

Fig. 10. Soil saturation estimated by mass balance at daily timescale, starting from 18 May 2010 (before the $13 \mathrm{~mm}$ rainfall event) and soil saturation measured by fixed TDR probes. Left panel: fallow plot. Right panel: cultivated plot.

$2.5 \mathrm{~mm} \mathrm{~d}^{-1}$, respectively) and confirms that all the irrigation water infiltrated in the fallow plot, in contrast with the previous interpretation of the infiltration experiment provided by (Cassiani et al., 2012).

\subsection{Model outcome}

In order to discuss our intuition on the mechanistic behavior of the plots, we modeled the dynamics of the infiltration experiment in the fallow plot and in the cultivated plot for comparison. In the fallow plot, we set the weed cover at its upper limit (evaluated by VIA), $\mathrm{CC}=0.4$. In the cultivated plot, $\mathrm{CC}=1$. The measured water content values before rainfall and irrigation were used to define the initial condition.

The model was forced by climatic data (precipitation, relative humidity, temperature, wind speed and solar radiation) recorded at a meteorological station located within the San Michele farm. The water balance of the two plots was estimated for 7 days starting 1 day before irrigation, using Eqs. (2) and (4), and the simulation results were compared with the fixed TDR measurements.

In Fig. 10, the calculated $S_{\mathrm{u}}$ and $S_{\mathrm{d}}$ are shown together with the soil moisture measurements obtained by fixed TDR. The measured soil saturation of the fallow plot was extremely variable after irrigation (Fig. 10, left panel), supporting the hypothesis that some local preferential infiltration occurred. The blue squares, corresponding to the $50 \mathrm{~cm}$ TDR probes, approached the calculated $S_{\mathrm{u}}$ (black line) shortly after irrigation, suggesting that water could infiltrate very quickly into the DSL. One day after irrigation the data were less scattered, and reasonably set around the calculated $S_{\mathrm{d}}$ (red line), confirming that redistribution occurred. In the cultivated soil (Fig. 10, right panel), $S_{\mathrm{d}}$ was initially low, the DSL was refilled by irrigation and slowly emptied by transpiration. The model shows how, after irrigation, the soil saturation of the two plots looks similar, according to the new interpretation of the ERT data proposed in this paper. There is at least a qualitative agreement between the TDR measurements and the simulated $S_{\mathrm{d}}$ of the two plots, suggesting that local scale processes, that are typical of the fallow plot, are missed, but the average soil moisture dynamics is reasonably captured by our simple model.

We conjectured that the presence of a crust over the bare plot could limit the water flux from the USL to the DSL, but the growth of weeds created a crust discontinuity and transformed the USL in a dual porosity layer, locally allowing the deep percolation of water in the DSL. The weed survival should be linked to this preferential local infiltration. We tried to explore the relevance of this positive feedback on the yearly water balance by running the model for the whole of 2010 (the year of the infiltration experiment). We assumed the weed to be active in between day of the year (DOY) 80 and DOY 274 and integrated Eqs. (2) and (4) between 1 January 2009 and 31 December 2010. Just the results of the calculation corresponding to the year of the experiment are shown in Fig. 11, where DOY $=1$ is 1 January 2010 and DOY $=365$ is 31 December 2010. The system loses memory of the initial condition after less than 200 days, thus the results shown in Fig. 11 are independent from the initial condition at 1 January 2009.

Two different scenarios are compared in Fig. 11: $\mathrm{CC}=0.4$, and the case of completely bare soil with deep percolation impeded $L_{\mathrm{u}}=0 \mathrm{~mm} \mathrm{~d}^{-1}$. In the case $\mathrm{CC}=0$ (blue and green lines) the water balance reduces to $P=\mathrm{RO}+E$ in the USL, all transpirable water was depleted at the beginning of the calculation, and since the DSL is not active, the soil saturation remains constant and represents a reference value to be compared with the calculated soil saturation in case $\mathrm{CC}=0.4$. According to our modeling assumptions, the USL is saturated by each rainfall event and slowly loses water via evaporation with $S_{\mathrm{u}}=1$ often during the winter season (blue line). During the dry summer period when the vegetation is water stressed, the saturation of the DSL in case CC $=0.4$ 


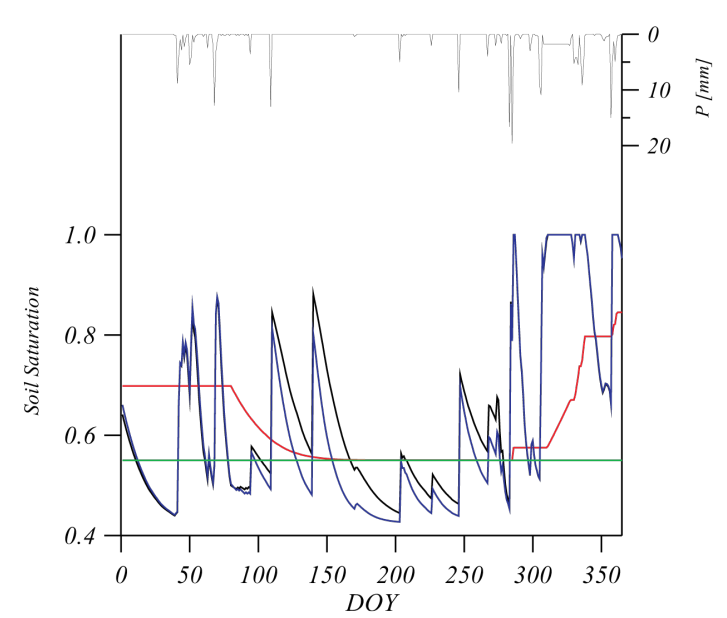

Fig. 11. Model outcome for the whole year 2010: DSL's soil saturation $S_{\mathrm{d}}$ and USL's soil saturation $S_{\mathrm{u}}$ versus time, for extreme values of the measured vegetation cover: $\mathrm{CC}=0$ and $\mathrm{CC}=0.4$.

approaches the complete depletion of the case $\mathrm{CC}=0$ that is taken here as a reference value (the red and the green lines coincide between DOY 180 and DOY 280). During the summer season, $S_{\mathrm{u}}$ is higher for CC $=0.4$ (black line) than for $\mathrm{CC}=0$ (blue line) due to the vegetation shadowing, whereas during the wet season, $S_{\mathrm{u}}$ is higher when $\mathrm{CC}=0$ (blue line) due to the fact that when CC $=0.4$, the USL transfers water to the DSL that acts as a reservoir and the vegetation facilitates the infiltration.

The situation that was observed at the beginning of our irrigation experiment corresponds to the calculated one at DOY 110 , for $\mathrm{CC}=0.4$, with most winter rainfall stored in the DSL and $S_{\mathrm{u}}<S_{\mathrm{d}}$ before rainfall. According to previous studies conducted in Mediterranean catchments where transpiration and storm flow are out of phase (Brooks et al., 2003), two water compartments interact in the subsoil: a matrix with small pore with low matrix potential, and fast flow paths originating from the interaction between vegetation growth and soil structural change. The fine-grained soil matrix is filled by heavy precipitation events (possibly occurring in autumn) or irrigation (as in our experimental setup) to be dried by the vegetation during the rainless season, thus, exchanging water with the fast flow paths through absorption.

In summary, we assumed that when $\mathrm{CC}=0.4$ (black and red lines), the vegetation roots alter the structure of the USL that transfers water to the lower soil layers during the winter season where it is stored. As a consequence, the USL maintains the DSL hydrologically active, supporting the later vegetation establishment and transpiration from the DSL. By time-averaging the calculated relevant water fluxes over the whole year 2010 , we found that $72 \%$ of the mean annual rainfall evaporated and $27 \%$ was transpired, while deep percolation was negligible, suggesting that $\mathrm{CC}=0.4$ could be the maximum achievable vegetation cover given the scarce water resources, leading to minor runoff losses. According to Cassiani et al. (2012), we suppose that $\mathrm{CC}=0.4$ could correspond to some threshold dictated by the scarce water availability, and CC could be different if more water was supplied to the environment (the fallow plot is not irrigated and the vegetation relies on rainfall only).

\section{Conclusions}

A combined experimental and theoretical approach was used to investigate the existence and the relevance of positive feedbacks between weed growth and infiltration on a fallow plot. The ERT data collected during an irrigation experiment (for a comprehensive description see Cassiani et al., 2012) evidenced that the infiltration flux in the fallow plot was more heterogeneous than in the cultivated plot and this fact could be dictated by the poor conductivity of the USL and by the macroporosity associated to the partial vegetation cover. Nevertheless, the fixed TDR data suggested that all the irrigation water infiltrated, and the coupled measurements of soil saturation and vegetation cover by mobile TDR and VIA did not evidence strong correlation between these two variables. Whether the infiltration is restricted by the crusty layer and enhanced by the vegetation in the fallow plot is unclear, due to the lack of a strong experimental evidence that confirm our intuition.

Relevant plant-soil-water interrelations that we tried to assess by repeated local measurements over a short timescale, were conceptualized in a modeling frame. The model captured the observed soil moisture dynamics during a 5-day irrigation experiment and was further used to investigate the impact of the positive feedback on the yearly water balance.

The results of our experimental and numerical research suggest that in the fallow plot (a) infiltration is heterogeneous and could be locally influenced by plant growth, (b) shortly after irrigation, redistribution takes place belowground where (c) roots have access to the whole active volume; (d) a positive feedback between infiltration and vegetation growth could maintain the DSL hydrologically active during the whole year; based on the model outcome, we may also state that (e) the interplay between vegetation growth and soil, which has an impact on the local hydrologic processes, affects the yearly water budget, reducing runoff and increasing the evapotranspiration, but leaving the groundwater recharge unaltered as compared to the bare soil situation.

The study of the soil-vegetation-atmosphere interaction certainly deserves special attention in arid and semiarid regions, where crop rotation, tillage and the natural transformation that the soil structure undergoes when it is left unseeded influence eco-hydrological connections that occur through lateral and overland flow, above- and belowground. Coupling hydrological and biological databases is a promising way to test modeling concepts for ecosystem dynamics and relevant processes that govern the ecosystem response to the external 
climate forcing, and this study may be considered a first step toward a better comprehension of the nature and relevance of possible soil-vegetation feedbacks.

Acknowledgements. We acknowledge funding from the EU FP7 Collaborative Project CLIMB "Climate Induced Changes on the Hydrology of Mediterranean Basins Reducing Uncertainty and Quantifying Risk" and from the MIUR PRIN project 2010JHF437 "Innovative methods for water resources management under hydro-climatic uncertainty scenarios".

Edited by: N. Romano

\section{References}

Alchanatis V., Cohen, Y., Cohen, S., Moller, M., Sprinstin, M., Meron, M., Tsipris, J., Saranga, Y. and Sela, E.: Evaluation of different approaches for estimating and mapping water crop status variability in cotton with thermal imaging, Prec. Agricult., 11, 27-41, doi:10.1007/s11119-009-9111-7, 2010.

Allen, R. G., Pereira, L. S., Raes, D., and M. Smith, M.: Crop evapotranspiration: Guidelines for computing crop water requirements, Irr. and Drain. Paper 56, UN-FAO, Rome, Italy, 1998.

ARPA Sardegna: Analisi Agro meteorologica e climatologica (Ottobre 2009-settembre 2010), 2001.

ARPA Sardegna: Analisi Agro meteorologica e climatologica (Ottobre 2010-settembre 2011), 2012.

Baudena, M., Andrea, F. D., and Provenzale, A.: A model for soilvegetation-atmosphere interactions in water-limited ecosystems, Water Resour. Res., 45, W02701, doi:10.1029/2008WR007172, 2009.

Binley, A.: http://www.es.lancs.ac.uk/people/amb/Freeware/ freeware.htm (last access: 4 December 2011), 2011.

Binley, A., Ramirez, A., and Daily, W.: Regularised image reconstruction of noisy electrical resistance tomography data, in: Process Tomography - 1995, edited by: Beck, M. S., Hoyle, B. S., Morris, M. A., Waterfall, R. C., and Williams, R. A., Proceedings of the 4th Workshop of the European Concerted Action on Process Tomography, 6-8 April 1995, Bergen, 401-410, 1995.

Binley, A., Henry-Poulter, S., and Shaw, B.: Examination of solute transport in an undisturbed soil column using electrical resistance tomography, Water Resour. Res., 32, 267, 125-146, doi:10.1029/95WR02995, 1996.

Binley, A. M., Cassiani, G., Middleton, R., and Winship, P.: Vadose zone flow model parameterisation using cross-borehole radar and resistivity imaging, J. Hydrol., 267, 147-159, 2002.

Borzuchowski, J. and Schulz, K. Retrieval of Leaf Area Index (LAI) and Soil Water Content (WC) Using Hyperspectral Remote Sensing under Controlled Glass House Conditions for Spring Barley and Sugar Beet, Remote Sens., 2, 1702-1721, doi:10.3390/rs2071702, 2010.

Brooks, J. R., Barnard, H., Coulombe, R., and McDonnell, J.: Ecohydrologic separation of water between trees and streams in a Mediterranean climate, Nat. Geosci., 3, 100-104, doi:10.1038/NGEO722, 2010.
Bushman, C. and Lichtenthaler, H. K.: Principles and characteristics of multi-color fluorescence imaging of plants, J. Plant Physiol., 152, 297-314, 1998.

Casper, B. B. and Jackson, R. B.: Plant competition underground, Annu. Rev. Ecol. System., 28, 545-570, 1997

Cassiani, G., Ursino, N., Deiana, R., Vignoli, G., Boaga, J., Rossi, M., Perri, M. T., Blaschek, M., Duttmann, R., Meyer, S., Ludwig, R., Soddu, A., Dietrich, P., and Werban, U.: Non-invasive monitoring of soil static characteristics and dynamic states: a case study highlighting vegetation effects, Vadose Zone J., doi:10.2136/vzj2011.0195, in press, 2012.

Cassiani, G., Bruno, V., Villa, A., Fusi, N., and Binley, A. M.: A saline trace test monitored via time-lapse surface electrical resistivity tomography, J. Appl. Geophys., 59, 244-259, 2006 a.

Cassiani, G., Binley, A. M., and Ferré, T. P. A.: Unsaturated zone processes, in: Applied Hydrogeophysics, NATO Sci, Ser. 51, edited by: Vereecken, H., Binley, A., Cassiani, G., Kharkhordin, I., Revil, A., and Titov, K., Springer-Verlag, Berlin, 75-116, $2006 b$.

Chaerle, L. and Van Der Straeten, D.: Seeing is believing: imaging techniques to monitor planet health, Biochim. Biophys. Acta, 1519, 153-166, 2001.

Cheng, H. D., Jiang, X. H., Sun, Y., and Wang, J.: Color image segmentation: advances and prospects, Pattern Recognit., 34, 22592281, 2001.

Cody, M. L.: Roots in plant ecology, Tree, 1, 76-78, 1986.

Deiana, R., Cassiani, G., Villa, A., Bagliani, A., and Bruno, V.: Calibration of a Vadose Zone Model Using Water Injection Monitored by GPR and Electrical Resistance Tomography, Vadose Zone J., 7, 215-226, 2008.

Franz, T. E., King, E. G., Caylor, K. K., and Robinson, D. A.: Coupling vegetation organization patterns to soil resource heterogeneity in a central Kenyan dryland using geophysical imagery, Water Resour. Res., 47, W07531, doi:10.1029/2010WR010127, 2011.

Garre, S. I., Coteur, C., Wongleecharoen, T., Kongkaew, J., Diels, J., and Vanderborght, J.: Noninvasive Monitoring of Soil Water Dynamics in Mixed Cropping Systems: A Case Study in Ratchaburi Province, Thailand, Vadose Zone J., 37, 1-28, doi:10.2136/vzj2012.0129, 2012.

Gimmi, T. and Ursino, N.: Mapping Material Distribution in a Heterogeneous Sand Tank by Image Analysis, Soil Sci. Soc. Am. J., 68, 1508-1514, 2004.

Gish, T. J. and Jury, W. A.: Effect of Plant Roots and Root Channels on Solute Transport, T. ASABE, 26, 440-444, 1983.

Graham, D. J., Reid, I., and Rice, S. P.: Automated Sizing of coarse grained sediments: Image Processing Procedures, Math. Geol., 37, 1-28, doi:10.1007/s11004-005-8745-x, 2005.

Graham, D. J., Rollet, A. J., Piegay, H., and Rice, S. P.: Maximizin the accuracy of image-based surface sediment sampling tecniques, Water Resour. Res., 46, W02508, doi:10.1029/2008WR006940, 2010.

Grayson, R. and Bloecshl, G.: Spatial patterns in catchment hydrology, Observations and modelling, Cambridge University Press, 2000.

Huisman, J. A., Hubbard, S. S., Redman, J. D., and Annan, A. P.: Measuring soil water content with ground penetrating radar: a review, Vadose Zone J., 2, 477-491, 2003. 
ITT Visual Information Solutions: IDL 7.1, www.ittvis.com (last access: December 2011), 2009.

Jackson, R. B., Jobbagy, E. G., and Nosetto, M. D.: Ecohydrology Bearings - Invited Commentary Ecohydrology in a human-dominated landscape, Ecohydrology, 2, 383-389, doi:10.1002/eco.81, 2009.

Keating, B. A., Gaydon, D., Huth, N. I., Probert, M. E., Verburg, K., Smith, C. J., and Bond, W.: Use of modelling to explore the water balance of dryland farming systems in the Murray-Darling Basin, Australia, Eur. J. Agron., 18, 159-169, 2012.

Kefi, S., Rietkerk, M., Alados, C. L., Pueyo, Y., Papanastasis, V. P., ElAich, A., and de Ruiter, P. C.: Spatial vegetation patterns and imminent desertification in Mediterranean arid ecosystems, Nature, 449, 213-215, doi:10.1038/nature06111, 2007.

Kemna, A., Vanderborght, J., Kulessa, B., and Vereecken, H.: Imaging and characterisation of subsurface solute transport using electrical resistivity tomography (ERT) and equivalent transport models, J. Hydro., 267, 125-146, 2002.

Kemna, A., Binley, A., Day-Lewis, F., Englert, A., Tezkan, B., Vanderborght, J., Vereecken, H., and Winship, P.: Solute transport processes, in: Applied Hydrogeophsics, edited by: Vereecken, H., Springer-Verlag, Berlin, 117-159, 2006.

Kurc, S. A. and Small, E. E.: Dynamics of evapotranspiration in semiarid grassland and shrubland during the summer monsoon season, central New Mexico, Water Resour. Res., 40, W09305, doi:10.1029/2004WR003068, 2004.

Kurc, S. A. and Small, E. E.: Soil moisture variations and ecosystem-scale fluxes of water and carbon in semiarid grassland and shrubland, Water Resour. Res., 43, W06416, doi:10.1029/2006WR005011, 2007.

Laliberte A.S., A. Rango, J.E. Herrick, Ed L. Fredrockson and L. Burkett (2007), An object-based image annalysis approach for determining fractional cover of senescent and green vegetation with digital plot photography, J. of Arid Environment, 69, 1-14, DOI:10.1016/j.jaridenv.2006.08.016.

Ludwig, R., Soddu, A., Duttmann, R., Baghdadi, N., Benabdallah, S., Deidda, R., Marrocu, M., Strunz, G., Wendland, F., Engin, G., Paniconi, C., Prettenthaler, F., Lajeunesse, I., Afifi, S., Cassiani, G., Bellin, A., Mabrouk, B., Bach, H., and Ammerl, T.: Climateinduced changes on the hydrology of mediterranean basins - a research concept to reduce uncertainty and quantify risk, Fresenius Environ. Bull., 19, 2379-2384, 2010.

MacQueen, J. B.: Some Methods for classification and Analysis of Multivariate Observations, Proceedings of 5-th Berkeley Symposium on Mathematical Statistics and Probability, Berkeley, University of California Press, Berkeley, CA, 281-297, 1967.

Marris, E.: More crop per drop, Nature, 452, 273-277, doi:10.1038/452273a, 2008.

Meron, M., Tsipris, J., Orlov, V., Alchanatis, V., and Cohen, Y.: Crop water stress mapping for site-specific irrigation by thermal imagery and artificial reference surfaces, Precis. Agricult., 11, 148-162, doi:10.1007/s11119-009-9153-x, 2010.

Mojid, M. A. and Cho, H.: Wetting Solution and Electrical Double Layer Contributions to Bulk Electrical Conductivity of Sand-Clay Mixtures, Vadose Zone J., 7, 972-980, doi:10.2136/vzj2007.0141, 2008.
Monego, M., Cassiani, G., Deiana, R., Putti, M., Passadore, G., and Altissimo, L.: Tracer test in a shallow heterogeneous aquifer monitored via time-lapse surface ERT, Geophysics, 75, WA61WA73, doi:10.1190/1.3474601, 2010.

Oxborough, K.: Imaging of chlorophyll a fluorescence: theoretical and practical aspects of an emerging technique for the monitoring of photosynthetic performance, J. Exp. Bot., 55, 1195-1205, doi:10.1093/jxb/erh145, 2004.

Penuelas, J. and Filella, I.: Visible and near-infrared reflectance techniques for diagnosing plant physiological status, Trends Plant Sci., 3, 151-156, 1998.

Perri, M. T., Cassiani, G., Gervasio, I., Deiana, R., and Binley, A. M.: A saline tracer test monitored via both surface and cross-borehole electrical resistivity tomography: comparison of time-lapse results, J. Appl. Geophys., 79, 6-16, doi:10.1016/j.jappgeo.2011.12.011, 2012.

Rietkerk, M., Brovkin, V., van Bodegom, P. M., Claussen, M., Dekker, S. C., Dikstra, H. A., Goryachkin, S. V., Kabat, P., van Nes, E. H., Neutel, A. M., Nicholson, S. E., Nobre, C., Petoukhov, V., Provenzale, A., Scheffer, M., and Seneviratne, S. I.: Local ecosystem feedbacks and critical transitions in the climate, Ecol. Complex., 8, 223-228, 2011.

Roth, K., Schulin, R., Flühler, H., and Attinger, W.: Calibration of time domain reflectometry for water content measurement using a composite dielectric approach, Water Resour. Res., 26, 22672273, doi:10.1029/WR026i010p02267, 1990.

Sadler, R. J., Hazelton, M., Boer, M. B., and Grierson, P.: Deriving state-and-transition models of semi-arid grassland dynamics using imagery, Ecol. Modell., 221, 433-444, 2010.

Schenk, H. J. and Jackson, R. B.: Rooting depths, lateral root spreads, and belowground/aboveground allometries of plants in water limited ecosystems, J. Ecol., 90, 480-494, doi:10.1046/j.1365-2745.2002.00682.x, 2002.

Strobbia, C. and Cassiani, G.: Multilayer ground-penetrating radar guided waves in shallow soil layers for estimating soil water content, Geophysics, 72, J17-J29, 2007.

Topp, G. C., Davis, J. L., and Annan, A. P.: Electromagnetic determination of soil water content: measurements in coaxial transmission lines, Water Resour. Res., 16, 574-582, 1980.

Ursino, N.: Modeling banded vegetation patterns in semiarid regions: Interdependence between biomass growth rate and relevant hydrological processes, Water Resour. Res., 43, W04412, doi:10.1029/2006WR005292, 2007.

Ursino, N.: Above and below ground biomass patterns in arid lands, Ecol. Modell., 220, 1411-1418, 2009.

Vanderborght, J., Huisman, J. A., van der Kruk, J., and Vereecken, H.: Geophysical Methods for Field-Scale Imaging of Root Zone Properties and Processes, in: Soil-Water-Root Processes: Advances in Tomography and Imaging, SSSSA Special Publication 61, edited by: Anderson, S. H. and Hopmans, J. W., SSSA, Madison, USA, doi:10.2136/sssaspecpub61.c12, 2013.

Winship, P., Binley, A., and Gomez, D.: Flow and transport in the unsaturated Sherwood Sandstone: characterization using crossborehole geophysical methods, in: Fluid Flow and Solute Movement in Sandstones: The Onshore UK Permo-Triassic Red Bed Sequence, edited by: Barker, R. D. and Tellam, J. H., Special Publications, Geological Society, London, 263, 219-231, 2006. 
Zhang, L., Dawes, W. R., and Walker, G. R.: Response of mean annual evapotranspiration changes at catchment scale, Water Resour. Res., 57, 701-708, 2001.
Zimmermann, B., Elsenbeer, H., and Moraes, J. M.: The influence of land-use changes on soil hydraulic properties: implications for runoff generation, Forest Ecol. Manage., 222, 29-38, 2006. 